\section{Prevalence of Pediatric Vestibular Disorders}

Prevalência da Doença Vestibular Pediátrica

Keywords: Child; Vestibular Diseases/epidemiology Palavras-chave: Criança; Doenças Vestibulares/epidemiologia

It was with great interest that we read the article by Lima AF et al. ${ }^{1}$ The authors investigated vertigo complaints in children under 18 years of age that were referred to a tertiary academic center.

The reported prevalence and etiologies of vestibular disorders can vary depending on the hospital department or clinic to which children are referred to, the referral criteria, the age range of the patients tested and the vestibular testing technologies that are available.

We have carried out a specific pediatric dizziness clinic in a tertiary academic center with a specialized pediatric hospital with most cases referred from Ears, Nose and Throat (ENT) consultants. From January 2014 to December 2019, we attended to 78 new pediatric patients with dizziness complaints. Our diagnoses differ substantially from the diagnoses in the study by Lima et al, especially in terms of the number of cases of psychogenic vertigo and benign paroxysmal positional vertigo (BPPV) (Table 1). Psychogenic vertigo is a prevalent diagnosis, especially in adolescent girls. As for primary BPPV, it is a very rare condition in children and anterior canal BPPV is even more so. ${ }^{2,3}$ We suspect that the cause for these differences might be a selection bias caused by nonconsecutive patient recruitment, as well as the difficulty in obtaining an accurate diagnosis in younger children.

We would also like to highlight the importance of the ophthalmic exam in pediatric patients, as this is the second most frequent cause of dizziness complaints in big centers and an aggravating factor in patients with the typical migraine equivalents. ${ }^{4}$

As for videonystagmography, we would like to stress that it is not the same as to performing caloric tests, and that in children, the rotatory chair is a very important test, especially in the early years of age. ${ }^{4,5}$

Regarding the patients diagnosed with vestibular neuritis, we do not understand why they all underwent imaging. If the head impulse, nystagmus, and Test-of-Skew - HINTS Protocol is followed as stated, the clinical history and physical examination should be the key elements to select which children with vertigo require neuroimaging. ${ }^{4}$ When caloric testing was carried out later and showed no hypofunction, it makes us wonder if these were rather cases of first attacks of vestibular migraine, even though we acknowledge that follow-up at one year shows a very high recovery rate. ${ }^{5}$ The authors did not mention the follow-up time.

\section{AUTHORS CONTRIBUTION}

AMA: Draft of the paper.

JCR: Critical review and approval of the final version of the paper.

\section{PROTECTION OF HUMANS AND ANIMALS}

The authors declare that the procedures were followed according to the regulations established by the Clinical Research and Ethics Committee and to the Helsinki Declaration of the World Medical Association updated in 2013.

\section{DATA CONFIDENTIALITY}

The authors declare having followed the protocols in use at their working center regarding patients' data publication.

\section{COMPETING INTERESTS}

The authors have declared that no competing interests exist.

\section{FUNDING SOURCES}

This research received no specific grant from any funding agency in the public, commercial, or not-for-profit sectors.

Table 1 - Pediatric population observed during a 5-year period in the Vestibular Clinic of the Hospital and University Centre of Coimbra Pediatric Hospital

\begin{tabular}{lc}
\hline & Total \\
& $(\mathrm{n}=78)$ \\
\hline Sex (female, $\mathrm{n} \%)$ & $45(57.7)$ \\
Age (mean, min - max) & $12.3(14-17)$ \\
Diagnosis $(\mathrm{n}, \%)$ & \\
Vestibular migraine & $23(29.5)$ \\
Psycogenic & $13(16.5)$ \\
Vestibular neuritis & $13(16.7)$ \\
BPVC & $3(3.8)$ \\
BPPV & $2(2.6)$ \\
Genetic syndrome & $5(5.1)$ \\
Mix diagnosis & $11(14.1)$ \\
Unknown peripheral vestibular disease & $9(12.8)$ \\
\hline
\end{tabular}

BPVI: benign paroxysmal vertigo of childhood; BPPV: benign paroxysmal positional vertigo 


\section{REFERENCES}

1. Lima A, Moreira F, Menezes A, Costa I, Azevedo C, Vilarinho S, et al. Patologia vestibular em idade pediátrica: análise retrospetiva e revisão da literatura. Acta Med Port. 2021;34:428-34

2. Lee J, Kim C, Hong S, Kim S, Suh M, Kim M, et al. Prevalence of vestibular and balance disorders in children and adolescents according to age: a multi-center study. Int J Pediatr Otorhinolaryngol. 2017;94:369 .

Ana Margarida AMORIM $\triangle^{1,2}$, João Carlos RIBEIRO ${ }^{1,2}$

1. Department of Otorhinolaryngology. Coimbra University Hospital Centre. Coimbra. Portugal.

2. Faculty of Medicine. University of Coimbra. Coimbra. Portugal.

Autor correspondente: Ana Margarida Amorim. marge c amorim@yahoo.com

Recebido: 29 de junho de 2021 - Aceite: 30 de junho de 2021 - Online issue published: 01 de setembro de 2021

Copyright @ Ordem dos Médicos 2021

https://doi.org/10.20344/amp.16788
3. Wiener-Vacher S, Quarez J, Priol A. epidemiology of vestibular impairments in a pediatric population. Semin Hear. 2018;39:229-42.

4. Kattah J. Use of HINTS in the acute vestibular syndrome. An overview. Stroke Vasc Neurol. 2018;3:190-6.

5. Wiener-Vacher S. Troubles de l'équilibre et vertiges de l'enfant. EMC Otorhinolaryngol. 2016;11:1-10. 